\title{
Um Estudo sobre a Influência do Jogo Black Stories na Prática e Aprendizagem de Levantamento de Requisitos de Software
}

\author{
Jorge Girão Limaverde Lima ${ }^{1}$, Andressa Bezerra Ferreira ${ }^{1}$ \\ ${ }^{1}$ Instituto Federal de Educação, Ciência e Tecnologia do Ceará \\ Fortaleza-CE, Brasil \\ \{jorgeglv11996@gmail.com, andressa.ferreira@ifce.edu.br\}
}

\begin{abstract}
Resumo: $O$ aprendizado e a prática da Engenharia de Requisitos requer diversas habilidades e competências de estudantes e profissionais da área de Engenharia de Software (ES). Dentre elas, podemos citar a capacidade de comunicação rápida, abstração e imersão. Mediante esse contexto, este trabalho busca apresentar um estudo sobre a influência do jogo Black Stories no desenvolvimento de tais competências. Para tanto, um grupo de alunos e ex-alunos de ES foi submetido a um experimento que consiste em partidas consecutivas do jogo. Após isso, foi constatada a influência positiva do jogo nas habilidades necessárias para o levantamento e descoberta de requisitos de software.
\end{abstract}

\begin{abstract}
Learning and practicing Requirements Engineering requires various skills and competencies from students and professionals in the area of Software Engineering (ES). Among them, we can mention a capacity for rapid communication, abstraction and immersion. In this context, this work seeks to present a study on the influence of the Black Stories game in the development of such skills. To this end, a group of students of ES was submitted to an experiment that consists of consecutive games of the game. After that, was determined the positive influence of the game on skills requires the survey and discovery of software requirements.
\end{abstract}

\section{Contextualização}

A Engenharia de Requisitos (ER) é o ramo da Engenharia de Software (ES) que estuda o conjunto de atividades e processos necessários para a elicitação, análise e especificação dos requisitos de um sistema de software. De acordo com (FERNÁNDEZ, 2017), tais requisitos são as descrições dos serviços que o sistema oferece e as restrições a seu funcionamento. Diante de tal contexto, é notável a importância de um bom processo de levantamento e descoberta de requisitos para o desenvolvimento e sucesso de um projeto de software.

Segundo (FERNÁNDEZ, 2017), identificar requisitos com qualidade, integridade, consistência e objetividade, é uma tarefa complexa que requer uma gama de conhecimentos e habilidades dos profissionais de ER. De acordo com (CALAZANS, 2017), dentre tais habilidades, podemos citar: boa capacidade de comunicação, resolução e análise de problemas, capacidade de abstração, mente criativa, dentre outras. Conforme aponta (MACHADO, 2020), tais características também podem ser observadas em jogadores experientes do jogo Black Stories (BS). 
BS é um jogo de cartas para dois ou mais jogadores que tem como objetivo a solução de enigmas através de perguntas e respostas. O baralho é formado por cinquenta cartas, cada uma com um título, imagens e enigmas únicos. A jogabilidade é simples. $\mathrm{Na}$ sua vez, o jogador compra uma das cartas do baralho e lê, na face da frente, o título e o texto de introdução do enigma em voz alta para os demais jogadores. A seguir, faz a leitura da solução do enigma no verso da carta, em silêncio. Esta deve ser mantida em segredo e em nenhum momento do jogo deve ser revelada ao grupo de jogadores. Então, a fim de decifrar o enigma, o grupo deve fazer perguntas para o jogador em posse da carta, que irá respondê-las apenas com: "Sim", "Não" ou "Irrelevante". O jogo termina quando o grupo de jogadores descreve o enigma em questão exatamente como descrito no verso da carta.

Mediante esse contexto, este trabalho tem como objetivo a realização de uma pesquisa acerca da influência que as experiências adquiridas ao jogar Black Stories têm sobre as habilidades e características necessárias para o aprendizado e prática das atividades de descoberta de requisitos em um projeto de software. Para tanto, será observada a autopercepção que um grupo de estudantes da área de tecnologia da informação têm a respeito de tais habilidades e como as mesmas podem ou não ser estimuladas por meio do jogo Black Stories. Espera-se, com tal estudo, contribuir para a área de ensino e aprendizagem em Engenharia de Requisitos de Software, no tocante a temática de descoberta de requisitos.

\section{Profissional de ER x Jogador de Black Stories: Habilidades convergentes}

Conforme mencionado na Seção 1, esta pesquisa busca relacionar e analisar as habilidades essenciais de um profissional ou estudante de requisitos de software com aquelas desenvolvidas por um jogador de Black Stories. Em sua dissertação de mestrado, Fortaleza (2013) mapeia habilidades importantes para o engenheiro de software relatadas na literatura. Da mesma forma, Do Vale (2011) fez uma revisão literária para a construção de uma lista de habilidades pessoais para profissionais que exercem atividades de descoberta de requisitos.

A Tabela 1 põe em evidência essas habilidades, dando uma breve descrição do que cada uma se trata.

Tabela 1. Habilidades essenciais a profissionais de ER e ES. Fontes: (FORTALEZA, 2013) (DO VALE, 2011)

\begin{tabular}{|c|c|}
\hline Habilidade & Descrição \\
\hline Comunicação & Comunicar-se de forma simples, concisa, não ambígua e de maneira que \\
facilmente se entenda.
\end{tabular}




\begin{tabular}{|c|c|}
\hline Pró-atividade & $\begin{array}{l}\text { Habilidade de se antecipar em ação, quando se faz necessário; identificar ou } \\
\text { resolver problemas por antecipação, com antecedência. }\end{array}$ \\
\hline Trabalho em equipe & $\begin{array}{c}\text { Capacidade de trabalhar com outras pessoas, identificando e atendendo suas } \\
\text { necessidades a fim de conseguir delas sua responsabilidade. }\end{array}$ \\
\hline Negociação & $\begin{array}{c}\text { Capacidade de encontrar um consenso em relação a temas, assuntos ou interesses } \\
\text { divergentes. }\end{array}$ \\
\hline Capacidade de imersão & $\begin{array}{c}\text { Habilidade para identificar e as necessidades de determinado cenário, } \\
\text { experiência ou situação. }\end{array}$ \\
\hline
\end{tabular}

De acordo com Mortensen (2017), Fonseca (2016) e Black (2019), por sua vez, durante uma partida do jogo Black Stories, os participantes são estimulados a exercitar diversas habilidades. Dentre as quais estão as apresentadas na Tabela 2.

Tabela 2. Habilidades e competências do jogador de BS. Fontes: Mortensen (2017), Fonseca (2016), Black (2019)

\begin{tabular}{|c|c|c|}
\hline Habilidade & Descrição & Referência \\
\hline Criatividade & Sair de procedimentos operacionais padrão, pensar "fora da caixa" & Fonseca (2016) \\
\hline Comunicação & Habilidade dos jogadores em fazer as perguntas certas & Fonseca (2016) \\
\hline Trabalho em grupo & $\begin{array}{c}\text { Agregar informações levantadas pelo grupo e colaborar na } \\
\text { descoberta de novas informações }\end{array}$ & Black (2019) \\
\hline Atenção a detalhes & Captar informações chave para a solução do mistério como um todo & Mortensen (2017) \\
\hline
\end{tabular}

Diante do exposto nas Tabelas 1 e 2, é possível perceber diversos pontos de convergência entre as habilidades necessárias para a descoberta de requisitos de software e aquelas estimuladas por meio do jogo BS. Com base em tais informações, delineia-se o experimento associado a esta pesquisa.

\section{O Experimento}

Nesta seção serão expostas as atividades utilizadas para a realização do experimento deste estudo, as mesmas consistem na aplicação de questionários e jogos com o intuito de identificar possíveis aperfeiçoamentos nas habilidades comuns à prática de descoberta de requisitos e ao jogador de BS. As subseções a seguir irão detalhar cada etapa deste experimento.

\subsection{Convite e Perfil dos Participantes}

O convite para a pesquisa foi feito por meio de um formulário divulgado nas redes sociais. Além de convidar voluntários para participar do experimento, o formulário serviu para coletar informações do perfil de cada participante. Ao todo, 10 estudantes aceitaram colaborar com o estudo. Os gráficos das Figuras 1, 2, 3 e 4 dizem respeito à formação acadêmica dos participantes informando, respectivamente, suas instituições de ensino, cursos, níveis e se tiveram alguma disciplina de engenharia de software. A Figura 5, por sua vez, mostra o grau de experiência que os participantes consideraram ter nas seguintes áreas: Engenharia de Software, Engenharia de requisitos, Elicitação de requisitos e Jogo Black Stories. 


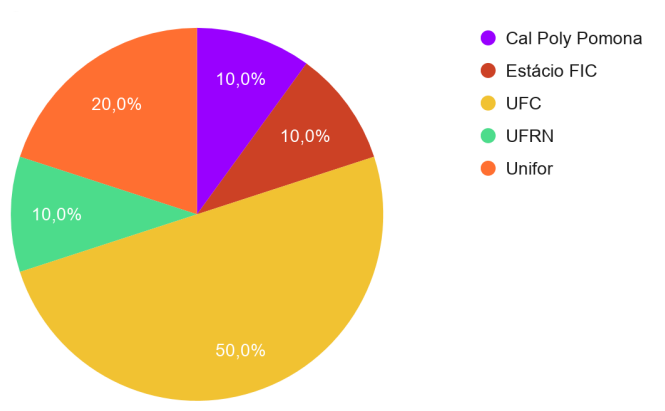

Figura 1: Instituições de ensino dos participantes.

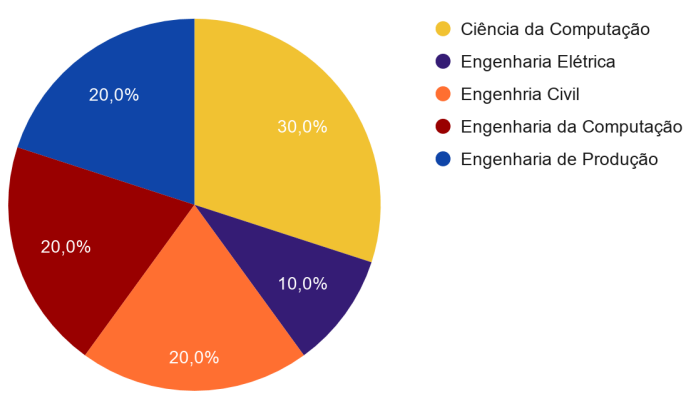

Figura 2: Cursos dos participantes.

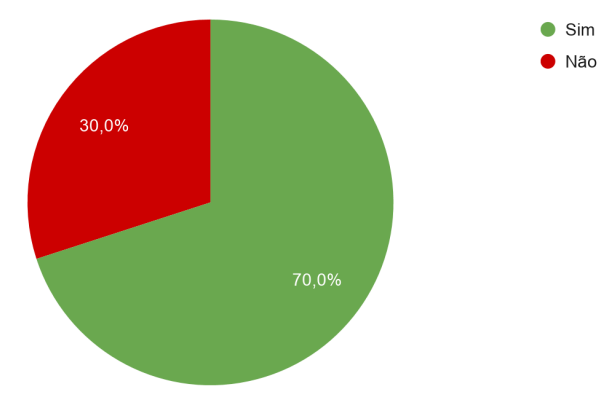

Figura 3: Níveis de ensino dos participantes.

Figura 4: Cursaram a disciplina de ES

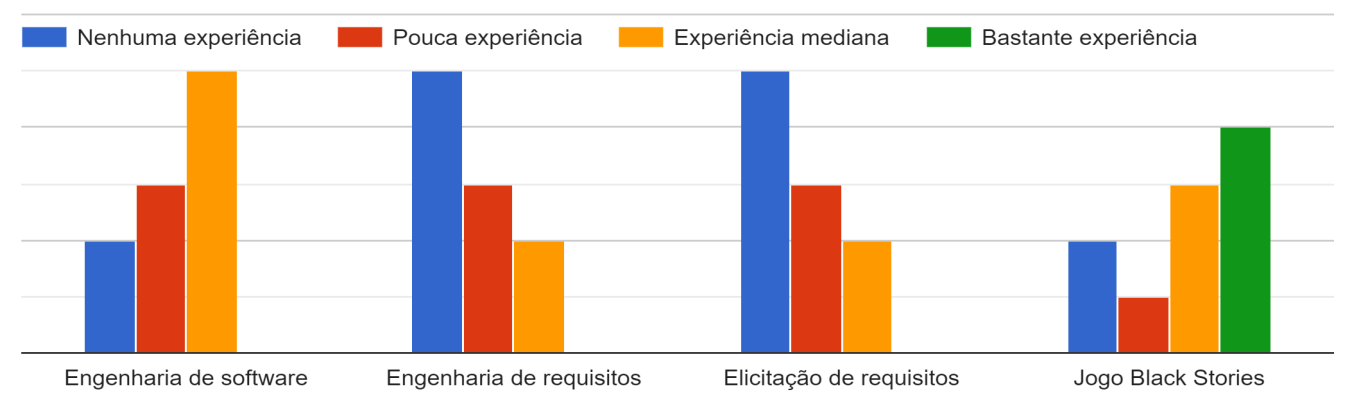

Figura 5: Gráfico de familiaridade dos participantes

Conforme é possível observar nos gráficos, a maioria dos participantes cursou a disciplina de ES, em nível de bacharelado, em cursos de graduação. Os mesmos consideram-se, em sua maioria, com experiência mediana em Engenharia de Software, nenhuma ou pouca experiência em Engenharia e Elicitação de Requisitos e mediana ou bastante experiência no jogo Black Stories.

\subsection{Agendamento e roteiro para condução dos jogos}

Os jogos foram agendados de acordo com a disponibilidade informada por cada participante em seu formulário de convite, de forma a juntar o maior grupo possível de jogadores por reunião. A Figura 6, a seguir demonstra o roteiro que foi seguido nas reuniões dos jogos, que aconteceram todas via Google Meet. 


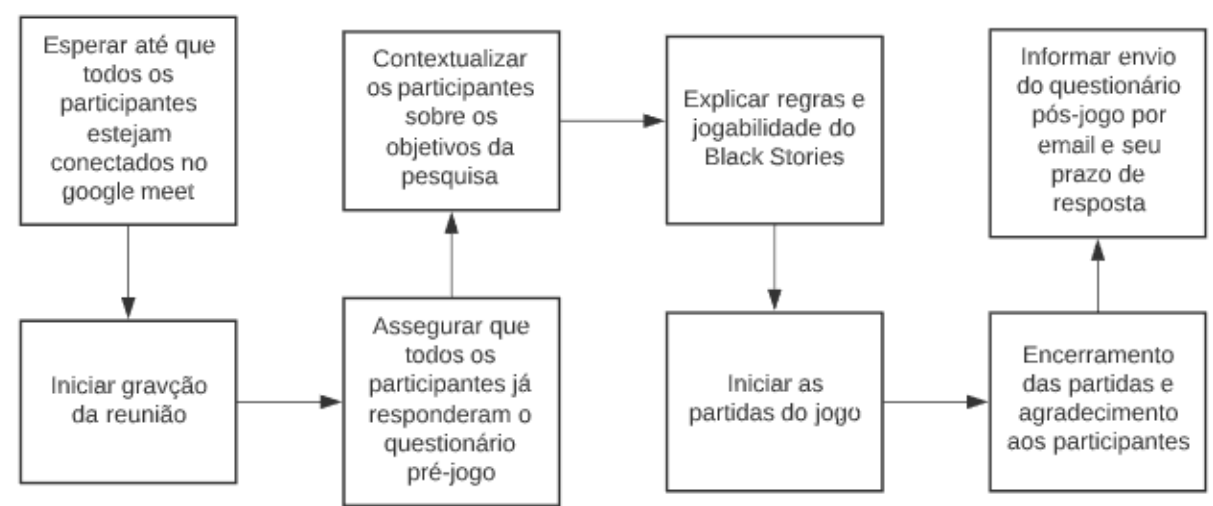

Figura 6: Fluxograma do Roteiro do Experimento. Fonte: próprio autor

Como é possível observar na Figura 6, após todos os participantes terem se conectado, foi iniciada a gravação da reunião e, em seguida, os participantes foram perguntados se já preencheram o questionário pré-jogo. Em caso negativo, foi dado um tempo para que o fizessem. Com os questionários preenchidos, os participantes foram contextualizados sobre os objetivos da pesquisa e as regras do Black Stories foram ensinadas para que as partidas pudessem ser iniciadas. Ao final, foram feitos os agradecimentos e despedidas aos participantes que não teriam mais jogos marcados. Aos demais foi reforçado o reencontro para as novas partidas. Além disso, todos foram avisados do questionário pós-jogo que seria posteriormente enviado por email e do prazo que teriam para respondê-lo.

\subsection{Questionários avaliativos}

Conforme mencionado na Seção 3.2, além do formulário de convite, os participantes do experimento tiveram que responder a dois questionários avaliativos, o questionário pré-jogo e o questionário pós-jogo. O questionário pré-jogo foi enviado por e-mail e aplicado como primeira etapa do experimento. Nele, os participantes auto avaliavam as habilidades que foram associadas como essenciais na Tabela 1, a fim de identificar como percebiam essas habilidades em si mesmos. O segundo, o questionário pós-jogo, também foi enviado por email, e tinha a finalidade de identificar possíveis influências do experimento nessas habilidades, bem como de coletar opiniões sobre a utilização do BS em ambiente acadêmico Os resultados obtidos nestes questionários serão explanados posteriormente nas Seções 4 e 5.

\section{Resultados Obtidos}

Os resultados obtidos no questionário pré-jogo podem ser observados na Figura 7, a seguir. As respostas se referem à pergunta: "Como você avalia sua habilidade nas seguintes competências?". 

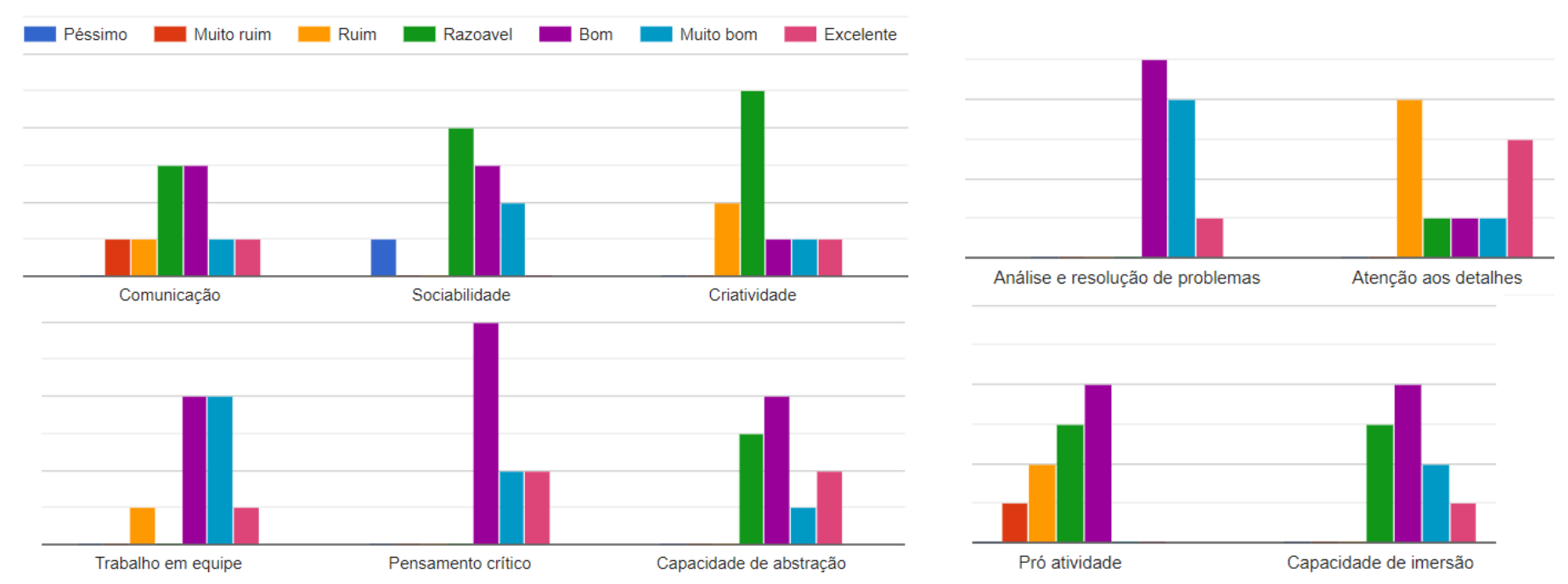

Figura 7: Resultados obtidos no questionário pré-jogo.

Os resultados obtidos no questionário pós-jogo podem ser observados na Figura 8 e é referente a pergunta: "Como você avalia a influência da experiência adquirida jogando Black Stories nas seguintes habilidades?”.

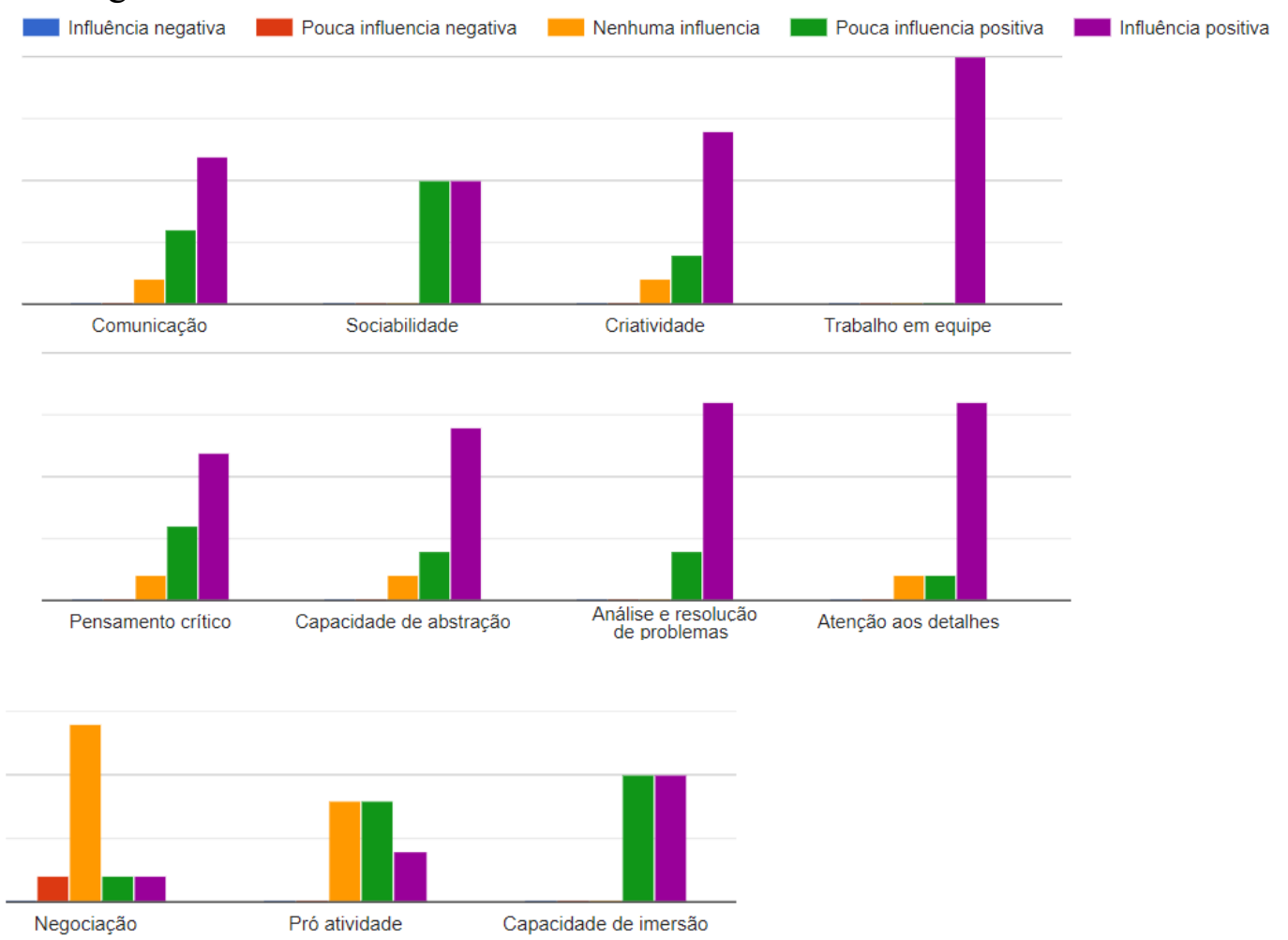

Figura 8:Resultados obtidos no questionário pós-jogo, influência do BS nas habilidades. Fonte: próprio autor

Conforme é possível observar nas Figuras 7 e 8 os participantes consideram, em sua maioria, que as habilidades analisadas foram impactadas positivamente pelo uso do Black Stories. Analisando as respostas dos participantes nos questionários de convite e pré-jogo percebe-se, inicialmente, que os participantes que afirmaram ter experiência mediana ou bastante experiência no BS tendem a avaliar melhor suas habilidades de comunicação, 
trabalho em equipe, análise e resolução de problemas e capacidade de imersão. Enquanto a maioria deles auto-avaliou essas habilidades como boas, muito boas ou excelentes, os participantes que afirmaram ter pouca ou nenhuma experiência com o jogo as avaliaram como ruins, razoáveis ou, no máximo, boas. Nas demais habilidades houve uma maior divergência nas respostas, não sendo possível identificar um padrão.

Ao analisar as respostas do questionário pós-jogo, ficou evidente a opinião dos participantes quanto a influência positiva trazida pela experiência para a habilidade de trabalho em equipe, sendo essa uma opinião unânime. Já para sociabilidade e capacidade de imersão, os participantes, em sua totalidade, consideraram ter sido influenciados positivamente pela experiência, em maior ou menor grau. Para as demais perícias, $70 \%$ ou mais dos participantes consideraram também positiva a influência na criatividade, na capacidade de abstração, na análise e resolução de problemas e na atenção aos detalhes.

Para as aptidões em comunicação e pensamento crítico, somente $10 \%$ dos participantes consideraram não haver influência. Negociação e pró-atividade foram as competências que tiveram a resposta "Nenhuma influência" mais presentes dentre as habilidades avaliadas e não foram citadas por nenhum dos participantes nas respostas subjetivas. Apesar disso, 60\% deles consideraram que o BS teve certa influência positiva para a pró-atividade. Considera-se relevante mencionar que $100 \%$ dos participantes acreditam que, no intuito de facilitar o entendimento dos alunos a respeito da elicitação de requisitos, o BS pode ser uma ferramenta utilizada em ambiente acadêmico.

Diante do exposto, pode-se afirmar que tais evidências percebidas durante a análise dos resultados obtidos reforçam o mote central desta pesquisa, de que o jogo Black Stories pode ser usado para desenvolvimento e aperfeiçoamento de competências necessárias para o estudante de levantamento de requisitos.

\section{Considerações Finais}

Conforme mencionado na Seção 5, por meio do estudo realizado nesta pesquisa notou-se que há, de fato, uma relação entre habilidades desenvolvidas pelo jogo BS e habilidades necessárias ao aprendizado e prática da elicitação de requisitos. Verificou-se também, por meio desta pesquisa, que há um autoproclamado aperfeiçoamento nessas competências por parte dos participantes colaboradores. Ademais, todos afirmaram que o BS traria benefícios se aplicado em sala de aula, no contexto de facilitar o entendimento dos alunos a respeito da elicitação de requisitos. No entanto, algumas limitações e perspectivas de trabalhos futuros se tornam relevantes.

A principal limitação desta pesquisa foi a dificuldade de encontrar participantes com disponibilidade para passar por todas as etapas da pesquisa. Apesar da divulgação, poucas pessoas responderam ao questionário de convite e, dessas, algumas não compareceram às reuniões ou não responderam aos questionários pré-jogo e pós-jogo, isso resultou em uma amostragem de apenas dez participantes. Não ignorando, também, a influência da pandemia de Covid-19, que impediu a captação de participantes presencialmente.

Diante de tal limitação, uma importante linha de pesquisa a ser abordada futuramente trata-se da análise da influência do BS em habilidades de participantes com pouca ou nenhuma experiência no jogo. Outra limitação do presente estudo é que todas as avaliações 
realizadas são feitas com base na autopercepção dos participantes. Em trabalhos futuros, um meio mais objetivo para avaliar criatividade, capacidade de abstração, capacidade de imersão, atenção aos detalhes, pensamento crítico, análise e resolução de problemas são os Testes de Pensamento Divergente, presentes em (CLAPHAM, 2011). Tais testes pressupõem que criatividade pode ser mensurada pedindo para que participantes identifiquem e resolvam problemas.

Por fim, no futuro, pode-se realizar uma pesquisa com alunos da disciplina de ES usando enigmas voltados para o levantamento de requisitos, onde o professor ou aplicador faria enigmas personalizados, cuja resposta seria um projeto de um software específico. Dessa forma, testando o impacto direto de BS na didática de habilidades voltadas para o levantamento de requisitos.

\section{REFERÊNCIAS}

BLACK Stories: diversão macabra para quem é bom de dedução!. In: Metropoly. [S. 1.], 23 out. 2019. Disponível

em: https://www.metropolybar.com.br/black-stories-diversao-macabra-para-quem-e-bom-de-deduca o/. Acesso em: 6 fev. 2021.

CALAZANS, Angélica Toffano Seidel, et al. O perfil do analista de requisitos de software: uma comparação entre a academia e o mercado de trabalho brasileiro. In: WER. 2017.

CLAPHAM, M.M. Testing/Measurement/Assessment. In. RUNCO, Mark. Encyclopedia of Creativity , Drake University, Des Moines, IA, USA, ano 2011, n. 2nd., p. 458-464, 3 out. 2011. DOI https://doi.org/10.1016/B978-0-12-375038-9.00220-X. Disponível em: 03/10/2011. Acesso em: 6 fev. 2021.

DO VALE, LUCIANO LEAL. A importância da qualidade profissional dos analistas de requisitos para o sucesso dos projetos de desenvolvimento de software: um estudo para identificar as habilidades mais relevantes. 2011.

FERNÁNDEZ, D.M., Wagner, S., Kalinowski, M. et al. Naming the pain in requirements engineering. 2017. https://doi.org/10.1007/s10664-016-9451-7

FONSECA, Renato. Black Stories - mais uma resenha descuidada. In: Reminiscências. [S. 1.], 2 fev. 2016.

https:/teclogos.wordpress.com/2016/02/02/black-stories-mais-uma-resenha-descuidada/.

Acesso em: 6 fev. 2021.

FORTALEZA, Luiz Leandro dos Reis, et al. Uma estratégia para o desenvolvimento de habilidades de comunicação e colaboração para futuros engenheiros de software. 2013.

MACHADO, Italo. Conheça o jogo Black Stories e proponha atividades em sala de aula. NotaTerapia, 2019.

Imagem.

Disponível

em:

http://notaterapia.com.br/2019/12/04/conheca-o-jogo-black-stories-e-proponha-atividades-em-sa la-de-aula/. Acesso em: 15 nov. 2020.

MORTENSEN , Eric. Black Stories Card Game review and rules. In: Geeky Hobbies. [S. 1.], 2017. Disponível em: http://www.geekyhobbies.com/black-stories-card-game-review-and-rules/. Acesso em: 6 fev. 2021. 